\title{
Influência da adubação potássica na qualidade e no potencial antioxidante do sapoti em diferentes estádios de desenvolvimento ${ }^{1}$
}

\author{
Laíse Nascimento Costa ${ }^{2 *}$, Patrícia Lígia Dantas de Morais², Grazianny Andrade Leite ${ }^{3}$, \\ Maria Lucilania Bezerra Almeida ${ }^{4}$, Maria Raquel Alcântara de Miranda ${ }^{5}$, Paula Lidiane de Oliveira Fernandes ${ }^{2}$
}

10.1590/0034-737X201764040011

\section{RESUMO}

A composição química e o estádio de maturação podem interferir no ponto de colheita do sapoti, a depender da destinação do fruto. Consequentemente, objetivou-se, com este trabalho, avaliar a influência da adubação potássica na qualidade e no potencial antioxidante do sapoti, em diferentes estádios de desenvolvimento. O experimento foi instalado na fazenda Norfruit, em Pau Branco, Mossoró, RN. O delineamento adotado foi em blocos casualizados, em esquema fatorial 5 x 6, composto por cinco doses de potássio $(0,200,400,600$ e $800 \mathrm{~g}$ de K por planta) e seis estádios de desenvolvimento, com cinco repetições. Os frutos foram marcados ao atingirem 10 a $15 \mathrm{~mm}$ de comprimento; sendo colhidos e avaliados $90,120,150,180$ e 200 dias após sua marcação e completamente maduros (após oito dias de armazenamento a $25 \pm 2{ }^{\circ} \mathrm{C} \mathrm{e} 58 \pm 5 \%$ UR). O sapoti pode ser colhido 200 dias após a floração plena, quando atinge seu tamanho máximo e apresenta qualidade adequada para o consumo. O sapoti maduro tem maior teor de açúcares e menor concentração de compostos bioativos e atividade antioxidante. A dose de $400 \mathrm{~g}$ por planta de $\mathrm{K}$ proporciona frutos de maior massa, com maiores concentrações de polifenóis extraíveis totais e atividade antioxidante. A atividade antioxidante do sapoti está mais correlacionada com a concentração de polifenóis extraíveis totais.

Palavras-chave: Manilkara zapota L.; nutrição potássica; desenvolvimento; compostos bioativos.

\section{ABSTRACT}

\section{Influence of potassium fertilization on quality and antioxidant potential of sapodilla at different development stages}

The chemical composition and stage of maturation may interfere with harvest point of sapodilla depending on the destination of the fruit. This study aimed at evaluating the influence of potassium fertilization on quality and antioxidant potential of sapodilla at different development stages. The experiment was carried out on farm Norfruit, in Pau Branco, Mossoró, RN. The experimental design was completely randomized blocks in a $5 \times 6$ factorial scheme, consisting of five doses of potassium $(0,200,400,600$, and $800 \mathrm{~g} \mathrm{~K}$ for plant $)$ and six development stages, with five repetitions. The fruits were marked when reaching 10 to $15 \mathrm{~mm}$ in length, being collected and evaluated after $90,120,150,180$, and 200 days after being marked and when they were fully mature (after eight days of storage at $25 \pm 2{ }^{\circ} \mathrm{C}$ and RH $58 \pm 5 \%$ ). Sapodilla can be harvested 200 days after full bloom, when it reaches its maximum size and presents adequate quality for consumption. The ripe sapodilla has higher concentration of sugar and lower concentration of bioactive compounds and antioxidant activity. The dose of $400 \mathrm{~g}$ of $\mathrm{K}$ per plant generated fruits of greater mass, with higher concentration of polyphenols and antioxidant activity. The antioxidant activity of sapodilla is more correlated with total extractable polyphenol concentration.

Key words: Manilkara zapota L.; potassium nutrition; development; bioactive compounds.

Submetido em 10/03/2015 e aprovado em 23/06/2017.

'Este trabalho é parte da dissertação de mestrado da primeira autora.

${ }^{2}$ Universidade Federal Rural do Semiárido, Programa de Pós-Graduação em Fitotecnia, Departamento de Ciências Vegetais, Mossoró, Rio Grande do Norte, Brasil. laisenc@ hotmail.com; plmorais@ hotmail.com; paula_esam@hotmail.com

${ }^{3}$ Universidade Federal Rural de Pernambuco, Cabo de Santo Agostinho, Pernambuco, Brasil. graziannyandrade@yahoo.com.br

${ }^{4}$ Universidade Federal do Ceará, Departamento de Fitotecnia, Fortaleza, Ceará, Brasil. lucilanialmeida@ @otmail.com

కUniversidade Federal do Ceará, Departamento de Bioquímica e Biologia molecular, Fortaleza, Ceará, Brasil. raquelamiranda@gmail.com

*Autora para correspondência: laisenc@ @otmail.com 


\section{INTRODUÇÃO}

O sapotizeiro (Manilkara zapota L) é nativo da América Central, mais especificamente do sul do México. No Brasil, esta espécie adaptou-se bem em praticamente todo o país. Entretanto, é na região Nordeste, que apresenta altas temperaturas e umidade, onde seu crescimento e produção são favorecidos (Bandeira et al., 2003).

O sapoti é um fruto tropical que apresenta potencial para exportação (Miranda et al., 2003). Segundo Silva Junior et al. (2014), no Brasil, a maior parte da produção desse fruto se dá no Nordeste, onde Pernambuco destaca-se como maior produtor nacional. Outros estados produtores são Bahia, Ceará, Pará, Paraíba, Rio Grande do Norte e Sergipe. Para aumentar a produção é de suma importância o estudo da nutrição mineral, fazendo o devido planejamento e os ajustes das doses de fertilização, a fim de produzir frutos de boa qualidade, com o menor custo possível. A adubação potássica beneficia a frutificação, sendo o potássio o nutriente requerido em maior quantidade pelo sapoti (Lederman et al., 2001).

A adubação é influenciada, ainda, pelas condições edafoclimáticas específicas de cada região. No município de Mossoró, RN, onde está localizado um importante polo agrícola produtor de sapoti, não existe estudo para adubação dessa cultura.

A qualidade e a composição química dos frutos podem ser afetadas pela adubação potássica e pelo estádio de desenvolvimento do fruto. O estudo da relação entre a composição química e o estádio de maturação é de grande importância, pois, dependendo da finalidade a que se destina o fruto, esses fatores podem interferir no seu ponto de colheita. Por exemplo, para fabricação de um suplemento, o qual exige alta concentração de polifenóis e capacidade antioxidante, um fruto imaturo seria o mais recomendado.

Contudo, ainda não se sabe como a adubação potássica afeta a qualidade e o potencial antioxidante ao longo do crescimento e da maturação do fruto do sapotizeiro. Por essa razão, objetivou-se, com este trabalho, avaliar a influência da adubação potássica na qualidade e no potencial antioxidante do sapoti, em diferentes estádios de desenvolvimento.

\section{MATERIAL E MÉTODOS}

O experimento com sapoti “Itapirema-31" foi realizado em um plantio comercial da Fazenda Norfruit, localizada em Pau Branco, zona rural de Mossoró, RN, de dezembro de 2010 a maio de 2012. O clima de Mossoró é semiárido, com temperaturas médias máxima de $28,4^{\circ} \mathrm{C}$, mínima de $27,3^{\circ} \mathrm{C}$ e média de $27,1^{\circ} \mathrm{C}$; umidade relativa média de $68,3 \%$; precipitação $765,8 \mathrm{~mm}$, no período do experimento, segundo a estação meteorológica da UFERSA, que fica a cerca de $30 \mathrm{~km}$ de distância da área experimental.
O pomar consistia de plantas enxertadas com média de oito anos de idade, estabelecidas em espaçamento de 7 x $7 \mathrm{~m}$, com 225 plantas por hectare, que apresentavam bom aspecto fitossanitário e eram irrigadas por microaspersão, com um aspersor por planta. O delineamento adotado foi em blocos casualizados, em esquema fatorial $5 \times 6$, composto por cinco doses de potássio e seis estádios de desenvolvimento, com cinco repetições, e avaliados dois frutos por repetição. No campo, cada parcela foi composta por cinco plantas, utilizando-se três plantas centrais na parcela útil. Isolaram-se as parcelas uma das outras por meio de uma linha de plantio paralela, em seus dois lados.

Antes da aplicação dos tratamentos, as plantas receberam poda de frutificação. Aplicaram-se cinco diferentes doses de potássio: 0, 200, 400, 600 e 800 g de K por planta, parceladas em três vezes (30, 90 e 120 dias após a poda de frutificação), na forma de cloreto de potássio ( $58 \%$ de $\left.\mathrm{K}_{2} \mathrm{O}\right)$. As plantas ainda receberam a mesma dose de nitrogênio e fósforo para todos os tratamentos, utilizando-se $1620 \mathrm{~g}$ por planta de ureia, aplicada em três parcelas juntamente com o potássio, e $682 \mathrm{~g}$ por planta de fosfato monoamônico granulado, em dose única na primeira adubação. A escolha das doses de adubação foi realizada com base na pesquisa de Lederman et al. (2001), com adubação para o sapotizeiro. Após a adubação e identificação da floração plena, os frutos foram marcados no campo quando alcançaram $10 \mathrm{a}$ $15 \mathrm{~mm}$ de diâmetro transversal, a fim de se obter homogeneidade de maturação. Os frutos foram colhidos aos 90, 120, 150, 180 e 200 dias após sua marcação em campo. Aos 200 dias, foi colhido o dobro do número de frutos, sendo metade analisada no dia da colheita e a outra metade armazenada no laboratório de pós-colheita da UFERSA, que é climatizado com ar condicionado. A temperatura durante o armazenamento foi de $25 \pm 2{ }^{\circ} \mathrm{Ce} 58 \pm$ $5 \%$ UR e os frutos foram analisados após oito dias, quando completamente maduros (208 dias).

Para os tratamentos com as doses de 0, 200, 400, 600 e $800 \mathrm{~g}$ de K por planta, em todos os estádios de desenvolvimento, foram realizadas as seguintes avaliações: tamanho, diâmetros transversais e longitudinais dos frutos, obtidos com paquímetro digital e expressos em centímetros; matéria fresca (g) dos frutos íntegros, medida em uma balança semianalítica; firmeza do fruto, determinada por meio de penetrômetro tipo Fruit Pressure Tester, com ponteira de $8 \mathrm{~mm}$ de diâmetro, sendo realizadas duas leituras por fruto, em lados opostos à região equatorial, obtendose a média em Newton $(\mathrm{N})$; teor de sólidos solúveis (SS, $\%$ ) da polpa processada, obtido por meio de refratômetro digital, conforme AOAC (2005); vitamina C (mg de ácido ascórbico $100 \mathrm{~g}^{-1}$ de polpa), determinada pelo método de Tilman, por titulação, segundo o método descrito por Strohecker \& Henning (1967). 
Para os tratamentos com as doses 0 (controle) e $400 \mathrm{~g}$ de K por planta para os frutos colhidos aos 120, 180 dias após a marcação e completamente maduros (208 dias), foram adicionadas as seguintes avaliações: açúcares solúveis (AS, \% glicose), determinados pelo método da antrona, segundo método descrito por Yemm \& Willis (1954); açúcares redutores (AR, \% glicose), extraídos em água destilada, sendo a determinação realizada segundo Miller (1959); pectinas totais e solúveis ( $\mathrm{mg} 100 \mathrm{~g}^{-1}$ ), extraídas pelo método descrito por Mccready \& Maccomb (1952) e quantificadas por espectrofotometria, de acordo com Blumenkrantz \& Asboe-Hansen (1973), sendo os resultados expressos em mg $100 \mathrm{~g}^{-1}$ de pectina na polpa; concentração de antocianinas totais e flavonoides amarelos (mg $\left.100 \mathrm{~g}^{-1}\right)$, determinados pelo método desenvolvido por Francis (1982); polifenóis extraíveis totais (PET, mg $100 \mathrm{~g}$ $\left.{ }^{1}\right)$, determinados com o método descrito por Larrauri et al. (1997); atividade antioxidante total (AAT, g fruta g DPPH $\left.{ }^{1}\right)$, determinada pela capacidade dos antioxidantes presentes na amostra de sequestrar o radical estável 2,2-difenil-1picrilhidrazila (DPPH), segundo o método descrito por Brand-Williams et al. (1995) e modificado por SánchezMoreno et al. (1998).

Os dados foram submetidos à análise de variância e análise com ajustamento de curvas para os dados quantitativos, sendo utilizados os programas SAS (Statistical Analysis System) e Bioestat 5.0. As médias foram comparadas pelo Teste de Tukey a $\mathrm{p}<0,01$ e $\mathrm{p}<0,05$. A relação entre atividade antioxidante e compostos bioativos foi obtida por meio da correlação de Pearson.

\section{RESULTADOS E DISCUSSÃO}

Observou-se efeito significativo da dose e do estádio de desenvolvimento para matéria fresca do fruto. Os frutos do tratamento controle mostraram menor massa do que os frutos submetidos à adubação. Os frutos atingiram maior massa aos 200 dias e a dose de 400 g de potássio por planta permitiu obter a maior massa $(195,75 \mathrm{~g}) \mathrm{e}$, o controle, a menor (174,93 g) (Figura 1A).

Após o armazenamento (208 dias), houve redução da massa do fruto, comparativamente à massa obtida aos 200 dias (Figura 1A). Essa redução deve-se, provavelmente, à perda de água por transpiração, durante o armazenamento dos frutos. Segundo Costa et al. (2004), a massa do fruto está relacionada linearmente com o seu grau de desenvolvimento e de maturação, exceto no estádio avançado de maturação.

A adubação potássica não influenciou nos diâmetros longitudinal e transversal dos frutos (Figura 1D e E). Aos 200 dias, os frutos alcançaram seu tamanho máximo com um diâmetro transversal de 7,04 cm e longitudinal de 6,92 $\mathrm{cm}$. Durante todo o desenvolvimento, o diâmetro trans- versal foi superior ao longitudinal, sendo a relação diâmetro transversal e longitudinal maior do que 1.

A adubação potássica não influenciou na firmeza dos frutos (Figura 1F). Os sapotis, nos estádios iniciais de desenvolvimento, encontravam-se extremamente firmes, imaturos, impossibilitando a determinação da firmeza antes dos 180 dias. A firmeza dos frutos reduziu-se com o avanço do estádio de maturação, com valores de 101,52 N, 91,48 $\mathrm{Ne} 27,12 \mathrm{~N}$, aos 180, 200 e 208 dias de desenvolvimento do fruto, respectivamente.

Essa redução deve-se, provavelmente, à degradação das protopectinas, alterando-se a constituição da parede celular e promovendo-se a dissolução dos componentes, o que causa o amaciamento dos frutos, o qual é consequência da desesterificação da pectina, catalisada pela enzima pectinametilesterase, seguida por despolimerização catalisada por poligalacturonase (Reyes et al., 2005).

A concentração de pectina solúvel aumentou, havendo diferenças entre os tempos de desenvolvimento e entre as doses (Tabela 1), enquanto a concentração de pectina total decresceu ao longo do amadurecimento, diferindo entre si em todos os tempos e doses (Tabela 2).

A concentração de pectina total está associado à firmeza do fruto. De acordo com Arruda et al. (2003), as pectinas fazem parte da lamela média e da parede primária da célula vegetal. Elas se solubilizam ao longo do desenvolvimento, mudando a estrutura e a composição da parede celular, tornando o fruto mais macio. Na presença do potássio, ocorre a redução da pectina total e, consequentemente, o aumento da pectina solúvel. Morais et al. (2008) verificaram, durante o amadurecimento de sapoti, concentrações de pectina total e solúvel superiores aos deste trabalho, assim como redução da concentração de pectina total, à medida que a pectina solúvel aumentava.

Os teores de sólidos solúveis aumentaram ao longo do desenvolvimento, atingindo os maiores valores (18,31 a 19,98\%) aos 208 dias (Figura 1B). Os sólidos solúveis têm sido utilizados como índice de maturidade para alguns frutos e indicam a quantidade de substâncias que se encontram dissolvidas no suco ou na polpa, constituídos principalmente por açúcares. Em geral, apresentam tendência a aumentar com a maturação. Valores superiores foram observados por Miranda et al. (2003), em sapoti do Vale do Curu, em que se observou variação de 18,5 a $25,3 \%$.

O teor de sólidos solúveis apresentou pouca variação com o aumento das doses de K. Apesar da pequena diferença, os frutos da dose de $400 \mathrm{~g}$ de K por planta apresentaram teor de sólidos solúveis superior aos das demais doses. O teor de SS nos frutos do tratamento controle, durante todo o desenvolvimento, apresentou-se inferior aos dos outros tratamentos, sendo que estes não diferi- 
ram entre si (Figura 1B). Esse aumento de sólidos solúveis na presença do potássio pode ser explicado por sua atuação na regulação da abertura estomática, relacionada diretamente com a eficiência da fotossíntese e, portanto, com a síntese de fotoassimilados, melhorando a qualidade dos frutos (Taiz \& Zeiger, 2004).

Houve interação significativa entre o tempo e a adubação potássica para vitamina C (Figura 1C). As maiores concentrações de vitamina $\mathrm{C}$ foram observadas aos 90 dias

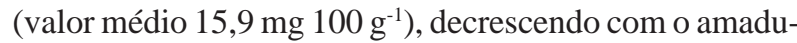
recimento dos frutos (valor médio de $10,38 \mathrm{mg} 100 \mathrm{~g}^{-1}$ ). A redução da concentração de vitamina $\mathrm{C}$ durante a maturação pode ser devida à oxidação dos ácidos e, consequentemente, à redução de vitamina $\mathrm{C}$, indicando a senescência do fruto (Oliveira et al., 2011).

Para os açúcares solúveis (Tabela 2) e redutores (Tabela 1), não houve influência da adubação potássica. Entretanto, eles aumentaram com a maturação dos frutos, apresentando os maiores valores aos 180 e 208 dias, não diferindo entre si. Esse aumento dos açúcares com o amadurecimento deve-se, provavelmente, à degradação do amido durante o processo de amadurecimento, o que é corroborado por Paliyath \& Murr (2008), ao afirmarem que concomitantemente com o catabolismo de amido,
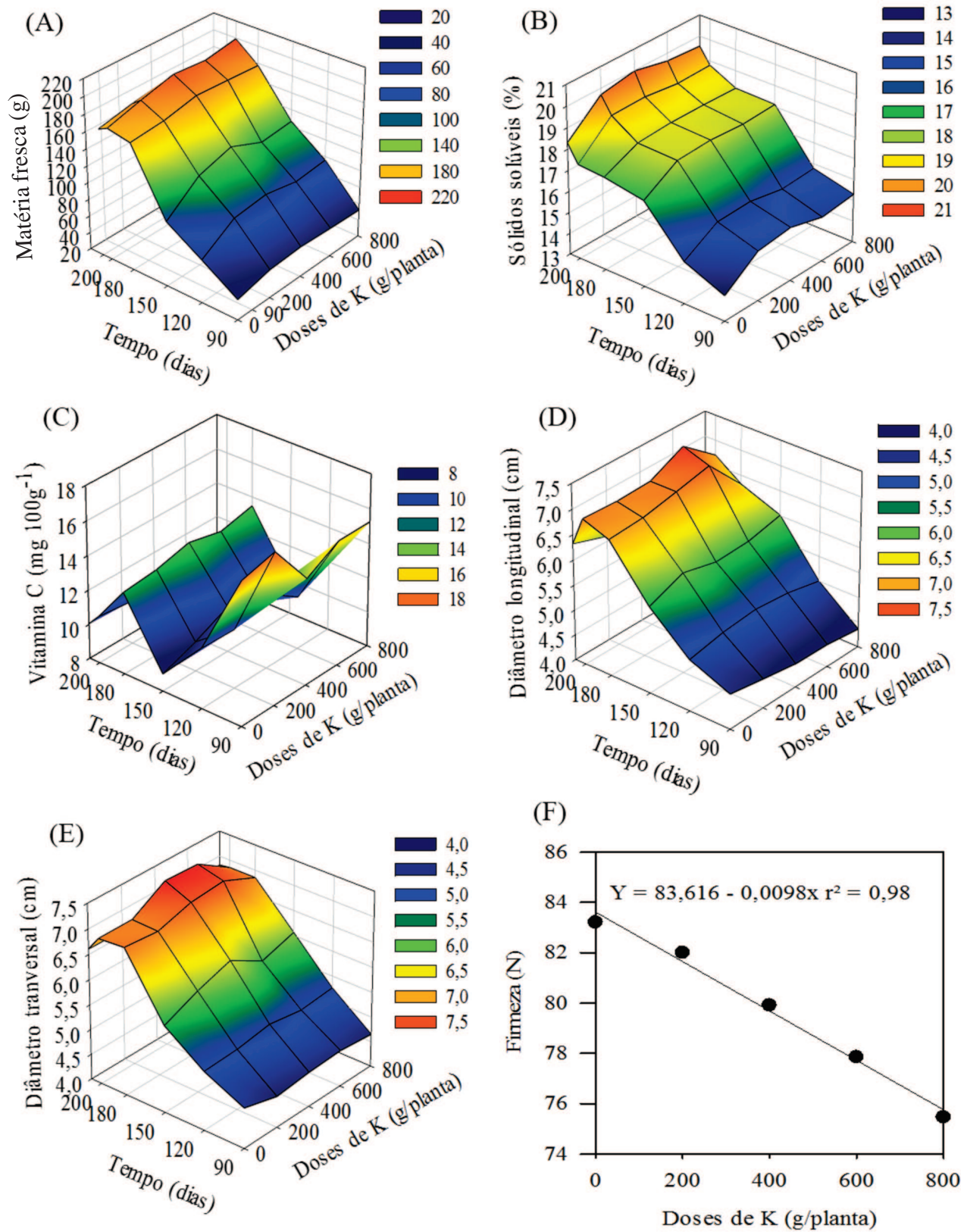

Figura 1: Matéria fresca (A), sólidos solúveis (B), vitamina C (C), diâmetro longitudinal (D), diâmetro transversal (E) e firmeza (F) dos frutos de sapotizeiro, em diferentes estádios de desenvolvimento, submetidos à adubação potássica. 
existe uma acumulação de açúcares, primeiramente de sacarose, glicose e frutose. De acordo com Miranda et al. (2003), o aumento dos açúcares redutores, ao longo do desenvolvimento do fruto, ocorre porque os frutos ligados à planta importam açúcares assimilados por fotossíntese.

Com o avanço do estádio de maturação, a concentração de polifenóis extraíveis totais (PET) decresceram, diferindo entre si. Quanto às doses, o tratamento de $400 \mathrm{~g}$ por planta de potássio apresentou maior concentração de PET do que o controle (Tabela 2). Isso pode ser explicado pelo fato de altas concentrações de potássio nos tecidos favorecerem a síntese e o acúmulo de compostos fenólicos (Perrenoud, 1990).

O potássio tem um papel importante na fotossíntese, atuando na produção de fotoassimilados. De acordo com Salgado et al. (2005), por meio da realocação de fotoassimilados, as plantas desviam carboidratos da via metabólica principal para a via metabólica secundária, visando, por exemplo, à produção de compostos fenólicos. Os metabolismos primário e secundário do carbono são dependentes da fotossíntese e da formação de carboidratos.
As concentrações de flavonoides e antocianinas decresceram durante a maturação e com o incremento das doses, sendo que todos os estágios de desenvolvimento do fruto e doses diferiram entre si. Os frutos do tratamento de $400 \mathrm{~g}$ de $\mathrm{K}$ apresentaram menores concentrações de flavonoides e antocianinas do que os do controle (Tabela 1).

A redução da concentração de compostos fenólicos durante o processo de amadurecimento dos sapotis também foi observada por Fernández et al. (2011) e Reyes et al. (2005). Ainda segundo os autores citados, essa redução durante a maturação ocorre por causa da oxidação de fenóis monohídrico e di-hídrico, diminuindo a concentração de compostos fenólicos ativos, por meio do aumento da atividade da polifenoloxidase, enzima que degrada os fenóis, durante o processo de maturação do sapoti, para formar quinonas, apresentando maior atividade no ponto de maturação adequada ao de consumo.

Para a atividade antioxidante, observou-se um aumento dos valores médios com o avanço do estádio de maturação, e redução, na presença da adubação potássica, diferindo em todos os estádios de maturação e doses. Os frutos do tratamento de $400 \mathrm{~g}$ de $\mathrm{K}$ apresentaram menores

Tabela 1: Açúcares redutores (\%), pectina solúvel (mg $\left.100 \mathrm{~g}^{-1}\right)$, flavonoides amarelos $\left(\mathrm{mg} 100 \mathrm{~g}^{-1}\right)$, antocianinas totais $\left(\mathrm{mg} 100 \mathrm{~g}^{-1}\right)$, atividade antioxidante $\left(\mathrm{g}\right.$ fruta $\left.\mathrm{g} \mathrm{DPPH}{ }^{-1}\right)$ dos frutos de sapotizeiro, em diferentes estádios de maturação, submetidos à adubação potássica

\begin{tabular}{lrrrr}
\hline \multirow{2}{*}{ Variável } & Doses (g/planta) & \multicolumn{3}{c}{ Tempo (dias) } \\
\cline { 3 - 5 } & 0 & $\mathbf{1 2 0}$ & $\mathbf{1 8 0}$ & $\mathbf{2 0 8}$ \\
\hline \multirow{2}{*}{ Açúcares redutores } & 400 & $5,23 \mathrm{Ba}$ & $8,42 \mathrm{Aa}$ & $11,04 \mathrm{Aa}$ \\
& 0 & $5,55 \mathrm{Ba}$ & $9,29 \mathrm{Aa}$ & $11,61 \mathrm{Aa}$ \\
\hline \multirow{2}{*}{ Pectina solúvel } & 400 & $141 \mathrm{Cb}$ & $167 \mathrm{Bb}$ & $198 \mathrm{Ab}$ \\
& 0 & $37,48 \mathrm{Aa}$ & $178 \mathrm{Ba}$ & $210 \mathrm{Aa}$ \\
\hline \multirow{2}{*}{ Flavonoides amarelos } & 400 & $27,18 \mathrm{Ab}$ & $19,32 \mathrm{Bb}$ & $6,25 \mathrm{Cb}$ \\
\hline \multirow{2}{*}{ Antocianina total } & 0 & $8,93 \mathrm{Aa}$ & $3,93 \mathrm{Ba}$ & $3,43 \mathrm{Ca}$ \\
& 400 & $5,91 \mathrm{Ab}$ & $2,59 \mathrm{Bb}$ & $1,17 \mathrm{Cb}$ \\
\hline \multirow{2}{*}{ Atividade antioxidante } & 0 & $559,63 \mathrm{Ca}$ & $919,82 \mathrm{Ba}$ & $1327,55 \mathrm{Aa}$ \\
& 400 & $548,56 \mathrm{Cb}$ & $872,40 \mathrm{Bb}$ & $1253,80 \mathrm{Ab}$ \\
\hline
\end{tabular}

Médias seguidas da mesma letra minúscula na coluna, e maiúscula na linha não diferem entre si pelo teste de Tukey a 0,05 de significância.

Tabela 2: Açúcares solúveis (\%), pectina total $\left(\mathrm{mg} 100 \mathrm{~g}^{-1}\right)$ e polifenóis extraíveis totais $\left(\mathrm{mg} 100 \mathrm{~g}^{-1}\right)$ dos frutos de sapotizeiro, em diferentes estádios de maturação, submetidos à adubação potássica

\begin{tabular}{lccc}
\hline Tempo (dias) & Açúcares solúveis & Pectina total & Polifenóis extraíveis totais \\
\hline 120 & $6,40 \mathrm{~b}$ & $392,5 \mathrm{a}$ & $1013,98 \mathrm{a}$ \\
180 & $11,35 \mathrm{a}$ & $315,5 \mathrm{~b}$ & $797,62 \mathrm{~b}$ \\
208 & $12,25 \mathrm{a}$ & $256,5 \mathrm{c}$ & $110,03 \mathrm{c}$ \\
\hline Doses (g/planta) & Açúcares solúveis & Pectina total & Polifenóis extraíveis totais \\
\hline 0 & $10,38 \mathrm{a}$ & $334 \mathrm{a}$ & $612,02 \mathrm{~b}$ \\
400 & $9,61 \mathrm{a}$ & $309 \mathrm{~b}$ & $669,07 \mathrm{a}$ \\
\hline
\end{tabular}

Médias seguidas de mesma letra na coluna não diferem entre si pelo teste de Tukey a 0,05 de significância. 
valores do que os do controle (Tabela 1). Quanto maior o valor médio da atividade antioxidante pelo método de DPPH, menor é a atividade antioxidante do fruto. Dessa forma, os resultados obtidos para a atividade antioxidante estão de acordo com os valores constatados para polifenóis, que aumentaram com a adubação potássica e reduziram-se com o avanço da maturação (Tabela 2), pois os compostos fenólicos são os principais constituintes da elevada atividade antioxidante do sapoti.

A atividade antioxidante serve para identificar o poder antioxidante dos compostos bioativos, os quais, de acordo com a Tabela 3, comportaram-se de forma similar, havendo correlação negativa significativa da atividade antioxidante com as concentrações de flavonoides e polifenóis. Dentre os compostos bioativos analisados, a vitamina $\mathrm{C}$ e as antocianinas não apresentaram correlação significativa com a atividade antioxidante do sapoti (Tabela 3).

Resultados semelhantes para correlação da atividade antioxidante com os compostos bioativos foram observados por Isabelle et al. (2010), que constataram que a vitamina $\mathrm{C}$ do sapoti é responsável por apenas $1,1 \%$ da atividade antioxidante, ao passo que Shui et al. (2004) encontraram uma elevada correlação entre a atividade antioxidante e compostos fenólicos totais do sapoti.

Tabela 3: Correlação de Pearson entre as variáveis: flavonoides amarelos (FL), antocianinas totais (AnT), polifenóis extraíveis total (PET), vitamina C (Vit. C) e com a atividade antioxidante total (AAT) de sapoti

\begin{tabular}{lcccc}
\hline & FL & AnT & PET & Vit. C \\
\hline AnT & $0.9011^{*}$ & & & \\
PET & $0.8751^{*}$ & $0.6311^{\text {ns }}$ & & \\
Vit. C & $0.6103^{\text {ns }}$ & $0.4384^{*}$ & $0.5321^{\text {ns }}$ & $-0.4372^{\text {ns }}$ \\
AAT & $-0.9068^{*}$ & $-0.7580^{\text {ns }}$ & $-0.9665^{* *}$ & - \\
\hline
\end{tabular}

Correlação significativa a $* 5 \%$ e $* * 1 \%$ de probabilidade. ${ }^{\text {ns }}$ não significativo.

\section{CONCLUSÃO}

O sapoti pode ser colhido 200 dias após a floração plena, quando atinge seu tamanho máximo e apresenta qualidade adequada para o consumo.

O sapoti maduro tem maior teor de açúcares e menor concentração de compostos bioativos e atividade antioxidante.

A dose de $400 \mathrm{~g}$ de $\mathrm{K}$ proporciona frutos de maior massa, com maiores concentrações de polifenóis extraíveis totais e atividade antioxidante.

A atividade antioxidante do sapoti está mais correlacionada com a concentração de polifenóis extraíveis totais.

\section{REFERÊNCIAS}

Arruda AMV, Pereira ES, Mizubuti IY \& Silva LDF (2003) Importância da fibra na nutrição de coelhos. Semina: Ciências Agrárias, 24:181-190.

AOAC - Association of Official Analytical Chemists (2005) Official methods of analysis of the association of official analytical chemists. $18^{\text {th }}$ ed. Maryland, AOAC. 1094p.

Bandeira CT, Mesquita ALM, Aquino ARL de, Cavalcanti Júnior AT, Santos FJS, Oliveira FNS, Souza Neto AJ de, Barros L de M, Braga Sobrinho R, Lima RN de \& Oliveira VH de (2003) O cultivo do sapotizeiro. Fortaleza, Embrapa Agroindústria Tropical. 20p. (Circular técnica, 13).

Blumenkrantz N \& Asboe-Hansen G (1973) New method for quantitative determination of uronic acids. Analytical Chemistry, 5:484-489.
Brand-Williams W, Cuvelier ME \& Berset C (1995) The phenolic constituents of Prunus domestica. I. The quantitative analysis of phenolic constituents. Lebensm Wiss Technology, 28:25-30.

Costa NP, Luz TLB, Gonçalves E P \& Bruno RLA (2004) Caracterização físico-química de frutos de umbuzeiro (spondias tuberosa Arr. Câm.), colhidos em quatro estádios de maturação. Bioscience Journal, 20:65-71.

Fernández NB, Veloz CS \& Duch ES (2011) Respiración y parámetros relacionados durante la maduración del chicozapote cosechado en la península de Yucatán. Revista Brasileira de Fruticultura, volume especial: 261-266.

Francis FJ (1982) Analysis of anthocyanins. In: Markakis P (Ed.) Anthocyanins as food colors. New York, Academic Press. p.181207.

Isabelle M, Lee BL, Lim MT, Koh WP, Huang D \& Ong CN (2010) Antioxidant activity and profiles of common fruits in Singapore. Food Chemistry, 123:77-84.

Larrauri JA, Ruperez P \& Saura-Calixto F (1997) Effect of drying temperature on the stabilitity of polyphenols and antioxidant activity of red grape pomace peels. Journal Agriculture Food Chemistry, 45:1390-1393.

Lederman IE, Silva Júnior JF, Bezerra JEF \& Moura RJM (2001) Sapotizeiro (Manilkara zopota L.von Royen). Jaboticabal, Sociedade Brasileira de Fruticultura. 71p.

Mccready RM \& Mccomb EA (1952) Extraction and determination of total pectic materials in fruit. Analytical Chemistry, 24:15861588 .

Miller G (1959) Use of dinitrosalicylic acid reagent for determination of reducing sugars. Analytical Chemistry, 31:426-428.

Miranda MRA, Benbadis AK, Filgueiras HAC \& Alves RE (2003) Alterações físicas e químicas durante o desenvolvimento e maturação do sapoti. Proceedings of the Interamerican Society for Tropical Horticulture, 47:259-261. 
Morais PLD, Lima LCO, Miranda MRA, Alves JD, Alves RE \& Silva JD (2008) Enzyme activities and pectin breakdown of sapodilla submitted to 1-methylcyclopropene. Pesquisa Agropecuária Brasileira, 43:15-20.

Oliveira VS, Afonso MRA \& Costa JMC (2011) Caracterização físico-química e comportamento higroscópico de sapoti liofilizado. Revista Ciência Agronômica, 42:342-348.

Paliyath G \& Murr DP (2008) Biochemistry of fruits. In: Paliyath G, Murr DP, Handa AK \& Lurie S (Eds.) Postharvest biology and technology of fruits, vegetables, and flowers. Ames, Wiley-Blackwell. p. 19-50.

Perrenoud S (1990) Potassium and plant health. $2^{\text {nd }}$ ed. Berne, International Potash Institute. 365p.

Reyes BB, Galarza MLA, Veloz CS \& Damián MTM (2005) Proceso de maduración de frutos de chicozapote [Manilkara zapota (L.) P. Royen] tipo fino. Revista Chapingo - Serie horticultura, 11:387-391.

Salgado PR, Favarin JL \& Leandro RA (2005) Fenóis totais nas folhas dreno e fonte de cafeeiro (Coffea arabica L.) com e sem produção. In: $4^{\circ}$ Simpósio de pesquisa dos cafés do Brasil, Londrina. Anais, SPCB. 347-350p.
Sánchez-Moreno C, Larrauri JA \& Saura-Calixto F (1998) A procedure to measure the antiradical efficiency of polyphenols. Journal Science Food Agriculture, 76:270-276.

Shui G, Wong SP \& Leong LP (2004) Characterization of antioxidants and change of antioxidant levels during storage of Manilkara zapota L. Journal of Agricultural and Food Chemistry, 52:7834-784.

Silva Junior JF da, Bezerra JEF, Lederman IE \& Moura RJM de (2014) O sapotizeiro no Brasil. Revista Brasileira de Fruticultura, 36:86-99.

Strohecker R \& Henning HM (1967) Analisis de vitaminas: métodos comprobados. Madrid, Paz Montalvo. 428p.

Taiz L \& Zeiger E (2004) Nutrição mineral. In: Taiz L \& Zeiger E (Ed.) Fisiologia vegetal. Porto Alegre, Artmed. p.95-113.

Yemm EW \& Willis AJ (1954) The estimation of carbohydrates in plant extracts by anthrone. Biochemical Journal, 57:508514 . 